\title{
Adoption of Augmented Reality Technologies in Tourism: Visitors' Acceptance of Smart Glasses: An Abstract
}

\author{
Aarash Baktash, Nina Krey, Vikneswaran Nair, and Philipp A. Rauschnabel
}

\begin{abstract}
To establish a competitive advantage, tourism destinations managers show a keen interest in new technologies to guide visitors. Recent developments indicate that a new form of wearable technologies, augmented reality smart glasses, might tremendously advance the tourism landscape. Yet, not much research has been done to understand this new form of technology. As a result, the literature lacks profound understanding of how visitors react to these wearable technological advances. Drawing on the theory of planned behavior and Hofstede's cultural framework, we develop a model to better understand usage intention of augmented reality smart glasses. Results of a survey among tourists vacationing in Malaysia show that (1) attitude, perceived behavior control, and social influences relate to usage intention and (2) several cultural variables moderate the strengths of these relationships.
\end{abstract}

References Available Upon Request

\footnotetext{
A. Baktash $(\bowtie) \cdot$ V. Nair

Taylor's University, Subang Jaya, Malaysia

e-mail: abaktash@gmail.com; vicky.nair@taylors.edu.my

N. Krey

Rowan University, Glassboro, NJ, USA

e-mail: krey@ rowan.edu

P.A. Rauschnabel

University of Michigan-Dearborn, Dearborn, MI, USA

e-mail: prausch@umich.edu
} 